\title{
Ethical Aspects of Organ Transplantation
}

Farhan Muhammad Qureshi

Dear Sir,

Organ transplantation has been a combination of the technical, the practical and the ethical since its initiation. Apart from the medical and surgical skillfulness and a sound knowledge of therapeutics and immunobiology, organ transplantation success requires not to harm to the recipient (patient) as well as the donor. Successful transplant attempt gives life and quality life to the organ recipients, however, there are issues such as organ trafficking, organ tourism and commercialism that serves to threat practically and ethically. Human organ trafficking is one of the most wicked crime committed and is believed to be the most profitable business globally ${ }^{1}$. Transplant tourism is the travelling of the welloff individual suffering from life threatening and irrevocable organ failure to other country usually poor country for organ transplantation ${ }^{2}$. Although commercialism is a part of our daily life nowadays and it is indispensable to a certain extent however, transplant commercialism is not only dangerous for recipients but also to their donors, physicians, surgeons as well as community. The Declaration on Organ Trafficking and Transplant Tourism of Istanbul defines as "ya policy or practice in which an organ is treated as a commodity, including by being bought or sold or used for material gain"3. Before launching of the renal transplant rule, Pakistan became the centre for illegal renal transplant for many years that includes Pakistan in one of the top five culprit countries for organ trafficking.

The fundamental principles of bioethics such as nonmaleficence, beneficence, health maximization, efficiency, respect for autonomy, justice are need to be in consideration before taking decisions for organ transplantation. The primary objective of the policy makers must be the health security of the recipients and the donors along with the integrity that should be respected. Every independent individual has the right to decide and make rational choices on his own benefit. However, assessment of risk and benefit are required for fair decisions and equality and equity among human beings.

Multiple factors has been involved in organ trafficking in Pakistan like poverty, unemployment, literacy, inaccessibility and unavailability of healthcare facilities, poor infrastructure and social services and neglecting the bill for human organ transplantation formulated in 2007 by Government of Pakistan. Organ trafficking and commercialism can be halt if implementation of the transplantation law follow efficiently. Health care facilities for the victims of organ trafficking especially post-operative cases should be improved.

\section{REFERENCES:}

1. Shelley, L.I. Human trafficking: A global perspective. Cambridge, UK: 2010; Cambridge University Press.

2. Khan MS. Organ Transplantation, Ethics, and Role of Medical Community and Media In Pakistan. Pakistan Journal of Public Health. 2018 Aug 5; 8(2):61-2.

3. Participants in the International Summit on Transplant Tourism. The Declaration of Istanbul on organ trafficking and transplant tourism. Transplantation 2008; 86: 103-106.

4. IRIN.Pakistan: Government mulls new law on Illegal Kidney sale 2007

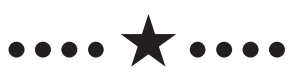

Farhan Muhammad Qureshi
Assistant Professor
Department of Community Health Sciences
Karachi Institute of Medical Sciences, Malir Cantt, Karachi
Email:drfarhanaureshi@hotmail.com
Received: 12-09-2018
Accepted: 16-10-2018 